\title{
Autophagy-like processes are involved in lipid droplet degradation in Auxenochlorella protothecoides during the heterotrophy-autotrophy transition
}

\section{Li Zhao, Junbiao Dai * and Qingyu Wu *}

MOE Key Laboratory of Bioinformatics, School of Life Sciences, Tsinghua University, Beijing, China

\section{Edited by:}

Jose Luis Crespo, Consejo Superior de Investigaciones Científicas, Spain

\section{Reviewed by:}

Ursula Goodenough, Washington

University, USA

Maria Esther Perez-Perez, CNRS,

France

\section{*Correspondence:}

Junbiao Dai, MOE Key Laboratory of

Bioinformatics, Center for

Epigenetics and Chromatin, School of Life Sciences, Tsinghua

University, Biotechnology Building

2-305, Beijing 100084, China

e-mail: jbdai@tsinghua.edu.cn;

Qingyu Wu, MOE Key Laboratory of

Bioinformatics, School of Life

Sciences, Tsinghua University,

Biotechnology Building 2-302,

Beijing 100084, China

e-mail: qingyu@mail.tsinghua.edu.cn
Autophagy is a cellular degradation process that recycles cytoplasmic components in eukaryotes. Although intensively studied in yeast, plants, and mammals, autophagy in microalgae is not well understood. Auxenochlorella protothecoides is a green microalga that has the ability to grow either autotrophically when under light or heterotrophically when in media containing glucose. The two growth modes are inter-convertible and transition between them is accompanied by drastic changes in morphology and cellular composition; however, the mechanisms underlying these changes are unknown. In this study, we identified autophagy-related genes and characterized their roles in the degradation of lipid droplets during the heterotrophy-to-autotrophy $(\mathrm{HA})$ transition in A. protothecoides. Most of the proteins constituting the eukaryotic "core machinery" were conserved in A. protothecoides. Two proteins, Atg4 and Atg8, were further investigated. A. protothecoides ATG4 was cloned from a cDNA library and expressed within yeast, and was able to functionally restore the autophagy pathway in atg $4 \Delta$ yeast during nitrogen starvation. Furthermore, Atg8, which displayed high sequence identity with its yeast homolog, was able to conjugate to phosphatidylethanolamine (PE) in vitro and was recruited to the phagophore assembly site in yeast. We also identified a C-terminal glycine residue, G118, that was the cleavage site for Atg4. Finally, we used confocal and transmission electron microscopy to reveal that autophagic-like vacuoles were detectable in algal cells during the HA transition. Our data suggested that the lipid droplets in heterotrophic cells were engulfed directly by the autophagic-like vacuole instead of via autophagosomes.

Keywords: Atg8, Atg4, autophagic vacuole, lipid droplet, microalgae

\section{INTRODUCTION}

All organisms need to adjust their growth and metabolic status according to changes in environmental and nutritional cues. Some organisms, named mixotrophs, have the ability to grow either autotrophically via photosynthesis or heterotrophically by utilizing organic carbon sources directly from the environment. Consequently, mixotroph cells display dramatic differences in their morphology and cellular composition under the two growth conditions. Auxenochlorella protothecoides, a free-living unicellular alga, grows under autotrophic conditions by forming a large cup-shaped chloroplast within the cell, and the cell largely consists of proteins and carbohydrates (Lu et al., 2013). When switched to heterotrophic conditions (limited nitrogen and abundant glucose), A. protothecoides grows rapidly and accumulates large amounts of lipid ( $>50 \%$ of dry cell weight). This lipid has been harnessed for the production of biofuel (Miao and Wu, 2006; Xiong et al., 2010; Lu et al., 2013). The two different growth modes are inter-convertible, and completely depend upon nutrient availability in the growth medium. A. protothecoides therefore provides a good model for the study of biogenesis and degradation of chloroplasts and the lipid body.
Autophagy is one of the two major degradative systems that eukaryotes employ for quality control of proteins and organelles (Lilienbaum, 2013). Three types of autophagy have been described so far: macroautophagy, microautophagy, and chaperone-mediated autophagy (CMA) (Mizushima, 2007). Autophagy has been intensively investigated in diverse organisms from the fungal, animal, and plant kingdoms and a large number of AuTophaGy-related (ATG) genes have been discovered (Tsukada and Ohsumi, 1993; Hanaoka et al., 2002; Yang and Klionsky, 2009; Xia et al., 2011). Studies on these ATG genes suggest that the core machinery of autophagy is highly conserved in eukaryotes (Meijer et al., 2007; Xia and Klionsky, 2007; Yang and Klionsky, 2009; Mizushima and Komatsu, 2011; Liu and Bassham, 2012).

Recently, several studies suggested that autophagy participates in the degradation of lipid droplets (LDs) (Singh et al., 2009; Kurusu et al., 2014; van Zutphen et al., 2014). LDs are welldefined organelles, delimited by a single protein-associated membrane, that mainly contain lipid esters, i.e., triacylglycerols (TAGs) and cholesteryl esters (Fujimoto and Parton, 2011). LDs are found in most cell types, including yeast, plant seeds, and adipocytes, 
but the lipid content is highly variable. In addition to the lipid storage function, LDs are involved in lipid metabolism and homeostasis, and have been implicated in several metabolic diseases. Singh et al. (2009) showed that LDs in mouse hepatocytes were degraded by macrolipophagy (the formation of autolipophagosomes and their delivery to the lysosomes). Similar processes were also reported in plants and fungi. For example, autophagydeficient mutants in rice exhibited delayed pollen maturation and male sterility as a result of blocked degradation of LDs in tapetum cells (Kurusu et al., 2014). In addition, autophagosome-like double membrane structures and vacuole-enclosed lipid droplets were observed during pollen maturation (Kurusu et al., 2014). In yeast cultured with oleic acid media and in Magnaporthe grisea during appressorium development, LDs were taken up by vacuoles in a process resembling microautophagy (Weber et al., 2001; van Zutphen et al., 2014).

Studies on autophagy in microalgae remain limited to date. A few recent studies presented the ultrastructure of autophagiclike vacuoles in some cells. Examined cells include Dunaliella primolecta in stationary phase, a photosynthesis-deficient mutant of Chlamydomonas reinhardtii, Micrasterias denticulate under salt or cadmium sulfate stress, Dunaliella viridis during nitrogen starvation, and the diatom Cyclotella meneghiniana treated with chlorinated benzenes or chromium (Eyden, 1975; Sicko-Goad et al., 1989; Lazinsky and Sicko-Goad, 1990; Inwood et al., 2008; Affenzeller et al., 2009; Jimenez et al., 2009; Andosch et al., 2012). In addition, C. reinhardtii Atg8 (CrAtg8) was identified and used as a specific marker for monitoring autophagy (Perez-Perez et al., 2010, 2012). Furthermore, we previously examined sequenced microalgae genomes and located most of the ATG-related genes described in other organisms. This suggests that the eukaryotic autophagy pathway may be conserved within these ancient unicellular organisms (Jiang et al., 2012).

In this study, we employed genomic analysis to identify ATG genes in A. protothecoides. We then conducted genetic and biochemical characterization of two of the autophagyrelated genes in the Atg8-conjugating pathway (ApATG8 and ApATG4). In addition, we demonstrated that autophagy was involved in the heterotroph-to-autotroph (HA) transition and provided evidence that lipid droplets in heterotrophic cells were degraded by the central vacuole in autophagy-like processes.

\section{MATERIALS AND METHODS ALGA STRAIN AND GROWTH CONDITIONS}

Auxenochlorella protothecoides sp.0710 was originally obtained from the Culture Collection of Alga at the University of Texas (Austin, USA). The culture media and methods of autotrophic and heterotrophic cells were performed as described by Xiong et al. (2010). For induction of the heterotrophy-autotrophy (HA) transition, cells were cultivated in heterotrophic media containing $30 \mathrm{~g} / \mathrm{l}$ glucose, $2 \mathrm{~g} / \mathrm{l}$ yeast extract and $0.1 \mathrm{~g} / \mathrm{l}$ glycine for 7 days and were then transformed into the autotrophic media supplied with light and aseptic air. The glucose and yeast extract were depleted and the glycine was added at the concentration of $5 \mathrm{~g} / \mathrm{L}$ in autotrophic media.

\section{IDENTIFICATION OF ApATG8 AND ApATG4}

The gene sequence annotations of ApATG8 and ApATG4 from whole genome data were confirmed using CD-search on NCBI. The multiple sequence alignment and 3D structure prediction were performed using Jalview and Swiss-model, respectively. Alignment of the 3D structure was constructed by PyMOL and phylogenetic analysis was conducted by MEGA4.

\section{RNA EXTRACTION AND REVERSE TRANSCRIPTION}

Seven-day-old heterotrophic liquid culture $\left(10 \mathrm{ml} ; \sim 1.8 \times 10^{8}\right.$ cells $/ \mathrm{ml}$ ) was harvested and frozen in liquid nitrogen for $20 \mathrm{~min}$. Cells were powdered using a mortar and pestle with a liquid nitrogen bath. Total RNA was extracted using Trizol (Invitrogen). For genomic DNA removal, $\sim 1 \mu$ g total RNA was treated in a $10 \mu \mathrm{l}$ reaction containing DNaseI, buffer with $\mathrm{MgCl}_{2}$ and nucleasefree water at $37^{\circ} \mathrm{C}$ for $30 \mathrm{~min}$. The reaction was stopped with the addition of $1 \mu \mathrm{l}$ of $50 \mathrm{mM}$ EDTA and incubation at $65^{\circ} \mathrm{C}$ for $10 \mathrm{~min}$. Reverse transcription was performed using a first strand cDNA synthesis kit (Fermentas). Genomic DNA-free template RNA $(0.1 \mu \mathrm{g})$ was added to a $20 \mu \mathrm{l}$ reaction containing buffer, oligo $(\mathrm{dT})_{18}$ primers, RNase inhibitor, dNTP mix, and reverse transcriptase. The reaction was incubated at $42^{\circ} \mathrm{C}$ for $60 \mathrm{~min}$ and terminated by incubation at $70^{\circ} \mathrm{C}$ for $5 \mathrm{~min}$.

\section{FUNCTIONAL COMPLEMENTATION OF ApAtg4 IN YEAST}

The ORF of ApATG4 was inserted into the vector pRS415 under the yeast $A D H 1$ promoter. The construct was transformed into yeast (BY4741 MATa his3 $\Delta 1$ leu $2 \Delta 0$ met15 $\Delta 0$ ura3 $\triangle 0$ atg4::KanMX4 pRS316 [GFP-ATG8 URA3]) using a standard lithium acetate protocol. Transformants were cultured in SC-uracil-leucine medium to log-phase and stained with FM464 for $30 \mathrm{~min}$ at $30^{\circ} \mathrm{C}$. Cells were chased in the same medium for $1 \mathrm{~h}$ at $30^{\circ} \mathrm{C}$ and then transformed into SD $(-\mathrm{N})$ medium for $4 \mathrm{~h}$. Cells were harvested after nitrogen starvation and observed using a confocal microscope (Leica TCS SP5) with GFP and TRITC filters.

\section{CLEAVAGE ASSAY OF ApAtg8 BY Atg4}

Three different forms of the ApAtg8 protein [wild type, glycine to alanine mutant $(\mathrm{G} 118 \mathrm{~A})$, and glycine deletion mutant $(\Delta \mathrm{G} 118)$ ] were fused to the N-terminal of GFP. Coding sequences were linked by overlapping extension PCR and the fusion constructs were inserted into vector pRS415 under the GAL10 promoter with an N-terminal polyhistidine tag. The construct was transformed into a yeast atg8 mutant (BY4741 MATa his3 $\Delta 1$ leu $2 \Delta 0$ met $15 \Delta 0$ ura3 $\Delta 0$ atg8::KanMX4) and expression was induced with $2 \%$ galactose for $2 \mathrm{~h}$. Yeast cells were subjected to immunoblot with anti-His antibody. For the in vitro cleavage assay, the ApAtg8-GFP, ApAtg4, and ScAtg4 sequences were cloned into vector pET21b and expressed in E. coli. Cells were homogenized by sonication. The reaction was conducted as previously described (Kirisako et al., 2000). The processing of ApAtg8 was detected by western blot using anti-GFP antibody.

\section{IN VITRO LIPIDATION OF Atg8}

Phospholipids for liposome preparation were purchased from Avanti Polar Lipids. Lipid mixtures consisting of 1-palmitoyl-2-oleoylphoshatidylcholine (POPC; 80\%) and 
dioleoylphosphatidylethanolamine (DOPE; 20\%) were prepared from stocks dissolved in chloroform. After transfer to a glass tube, the mixture was dried to a thin film under a stream of nitrogen. Samples were dried further in a desiccator under vacuum for more than $6 \mathrm{~h}$ to remove the traces of organic solvent. The resulting lipid film was hydrated in a buffer consisting of $20 \mathrm{mM}$ Tris- $\mathrm{HCl}(\mathrm{pH} 7.5)$ and $150 \mathrm{mM} \mathrm{NaCl}$ at room temperature for $1 \mathrm{~h}$ to produce large multilamellar vesicles (MLVs). MLV suspensions were then disrupted by several freeze-thaw cycles (A single freeze-thaw cycle consisted of freezing for $3 \mathrm{~min}$ at liquid nitrogen temperature $\left(-196^{\circ} \mathrm{C}\right)$ and thawing for $3 \mathrm{~min}$ in a water bath at $42^{\circ} \mathrm{C}$ ). The lipid suspension was then extruded through two polycarbonate membranes (Whatman) of $400 \mathrm{~nm}$ pore size using the Avanti Mini-Extruder at room temperature. Liposomes were stored at $4^{\circ} \mathrm{C}$.

In vitro lipidation of Atg8 was conducted using purified Atg3, Atg5, Atg7, Atg8, Atg12, and liposomes. The ApAtg8 protein was purified using HIS-Select Nickel Affinity Gel (Sigma). Reactions were performed as previously described (Ichimura et al., 2004). To distinguish Atg8 and Atg8-PE, the reaction products were subjected to $13.5 \%$ urea-SDS-PAGE and stained with Coomassie blue.

\section{CO-LOCALIZATION OF Atg8 WITH Ape1}

GFP-ApATG8 and Ape1-mCherry were inserted into pRS416 and pRS415, respectively, under the control of the $A D H 1$ promoter. Yeast atg $8 \Delta$ cells were co-transformed with these two plasmids. Transformants were cultured to log-phase in SC-uracil-leucine medium at $30^{\circ} \mathrm{C}$, washed three times, and resuspended in SCuracil-leucine medium containing $0.2 \mu \mathrm{g} / \mathrm{ml}$ rapamycin for $1 \mathrm{~h}$ at $30^{\circ} \mathrm{C}$. Cells were harvested and observed using a Zeiss710META microscope using eGFP and mCherry filters.

\section{MONODANSYLCADAVERINE AND NILE RED STAINING}

For monodansylcadaverine and Nile red staining, algal cells were harvested and washed with $100 \mathrm{mM}$ PBS (pH6.8) three times. Cells were stained for $10 \mathrm{~min}$ with $0.5 \mathrm{mM}$ monodansylcadaverine dissolved in water (Sigma-Aldrich) at room temperature or with $1 \mu \mathrm{g} / \mathrm{ml}$ Nile red dissolved in DMSO (Genmed Scientifics) at $37^{\circ} \mathrm{C}$. Cells were then washed with PBS three times to remove excess fluorescent dyes. Cells were observed using a Zeiss710META microscope with dansylcadaverine, Nile red, and chlorophyll A filters. The MDC-incorporated structures were excited at $405 \mathrm{~nm}$ and detected at 451-539 nm. Fluorescence intensity was measured using ImageJ. The original images of HA cells stained with MDC were transformed into 8-bit images and cellular regions were outlined using the threshold tools of ImageJ. Integrated density (IntDen) and area were measured. The final average fluorescent intensity per cell was calculated as IntDen/Area. Approximately 100 cells were measured.

\section{DETERMINATION OF TOTAL LIPID AND CHLOROPHYLL CONTENT IN ALGAL CELLS}

Algal cells were harvested, washed twice with distilled water, and lyophilized. Lipid in algal powder was transesterified into biodiesel with sulfuric acid and then measured using gas chromatography as previously described (Xiong et al., 2010). For chlorophyll analysis, algal powder was boiled in DMF $(\mathrm{N}, \mathrm{N}$ dimethylformamide) (Amresco) for $5 \mathrm{~min}$ for chlorophyll extraction, followed by measurement of $\mathrm{OD}_{663}$ and $\mathrm{OD}_{645}$ using UV/visible spectrophotometry (Pharmacia Biotech Ultrospec 2000, Sweden) as described previously (Xiong et al., 2010).

\section{TRANSMISSION ELECTRON MICROSCOPY}

A. protothecoides cells were fixed in $2.5 \%$ glutaraldehyde (pH6.8) for $12 \mathrm{~h}$ at $4^{\circ} \mathrm{C}$. Samples were prepared as described by Jiang et al. (2012). Cells were imaged using a transmission electron microscope (Hitachi, Japan).

\section{RESULTS}

\section{MOST OF THE CORE PROTEIN MACHINERY FOR AUTOPHAGY IS} CONSERVED IN A. PROTOTHECOIDES

Recently, we generated the complete genome sequence of $A$. protothecoides (Gao et al., 2014) and identified several hypothetical genes that were annotated as homologs of ATG genes. Next, we conducted a genome-wide protein BLAST analysis using yeast ATG proteins as query sequences. Each identified candidate was subjected to the CD-search at the National Center for Biotechnology Information (NCBI) data bank to confirm the presence of conserved autophagy protein domains. Eventually, we found that most of the identified autophagy-related genes (12 of 17) could be assigned to one of the core machineries that participated in different stages of autophagy. The assigned core machineries included membrane initiation, elongation, closure, and fusion with vacuoles, suggesting that $A$. protothecoides possessed the molecular components needed for autophagy induction. Unlike plants, only a single copy of each ATG gene was identified in the A. protothecoides genome. As shown in Figure 1, most of the putative genes had moderate but substantial identities (20-80\%) with the yeast homologs. All the identified proteins contained conserved ATG domains (data not shown). Notably, all of the components of the Atg8-conjugating pathway (Atg8, Atg4, Atg5, Atg7, Atg3, and Atg12) were identified in the A. protothecoides genome, suggesting that the pathway was likely to be active in this alga.

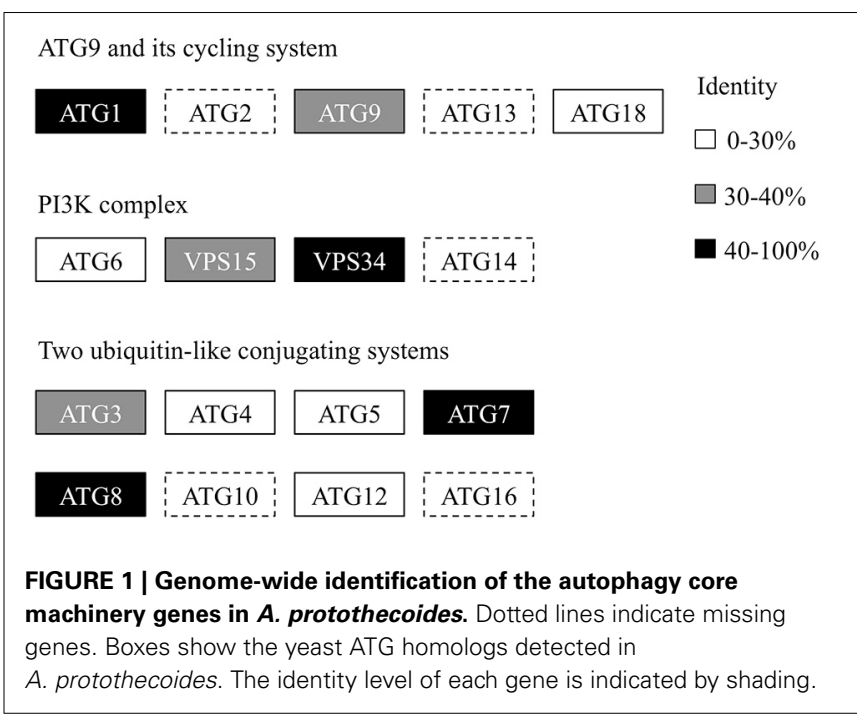




\section{IDENTIFICATION OF ApAtg8 AND ApAtg4}

To investigate whether an active autophagy pathway was present in A. protothecoides, we focused on characterization of two key components: ApATG4 and ApATG8. The putative ApATG8 and ApATG4 genes were amplified from a cDNA library using genespecific primers (Supplementary Table 1) and were cloned and sequenced. DNA sequence alignments between the cloned cDNA and the genomic DNA (gDNA) sequence revealed the gene structures of ApATG8 and ApATG4 (Figure 2A). The ApATG8 gene spanned approximately $2 \mathrm{~kb}$ of the genome and contained 6 exons and 5 introns. The ApATG4 gene was about $2.6 \mathrm{~kb}$ in length and had 8 exons and 7 introns. These gene structures closely resembled the structures of the plant homologs. The ApAtg8 protein also had a considerable degree of identity $(\sim 73 \%)$ with the yeast homolog. Several C-terminal Atg8 protein sequences from $A$. protothecoides and model organisms were aligned (Figure 2B). This analysis indicated that the C-terminal glycine residue of Atg8 at position 118, which is modified by Atg4 during autophagy induction, was conserved. The predicted ApAtg8 protein structure contained four $\alpha$-helices and four $\beta$-sheets and was consistent with the reported secondary structures of the yeast and human homologs. The predicted tertiary structure of ApAtg8, which consisted of an N-terminal $\alpha$-helix domain and a C-terminal ubiquitin-like core (Figure 2C), was similar to yeast Atg8 (resolved by NMR) and human LC3 (resolved by crystallization). Phylogenetic analysis of Atg8 proteins from $A$. protothecoides and model organisms indicated that ApAtg8 had the closest relationship to Atg8 from C. reinhardtii, which corresponded to the 16s rRNA phylogeny (Figure 2D). Taken together, these data indicate that Atg8 is conserved between eukaryotes.

\section{ApAtg4 CAN FUnCTIONALLY REPLACE Atg4 IN YEAST}

To confirm the function of the ApAtg4 protein, a complementation experiment was conducted in yeast. GFP-Atg8 was used as a marker of autophagy. The ApAtg4 protein was expressed in a yeast strain containing GFP-tagged Atg8 and a complete deletion of ATG4 $(\operatorname{atg} 4 \Delta)$. As shown in the top panel of Figure 3, Atg8 was not processed or translocated to the vacuole upon nitrogen starvation when an empty vector was supplied (i.e., no ApAtg4). Localization of GFP-tagged Atg8 was restored upon expression of yeast Atg 4 from a plasmid containing ScATG4 (middle panel). Localization of GFP-tagged Atg8 was similarly restored when ApATG4 was expressed (bottom panel). This indicated that ApAtg4 could functionally replace yeast Atg4 and restore the autophagy pathway under conditions of nitrogen starvation. ApAtg4 is therefore the homolog of yeast Atg4 and the two proteins probably perform similar functions during autophagy in their respective organisms.

\section{ApAtg8 IS CLEAVED BY Atg4 PROTEASE IN VITRO AND IN VIVO}

ApAtg4 functioned as a protease and was able to functionally replace yeast Atg4. We therefore hypothesized that ApAtg8 would be processed by cleavage at the C-terminal glycine residue as in yeast Atg4. As mentioned above, a highly conserved glycine residue was located at amino acid position 118 (G118) of ApAtg8,

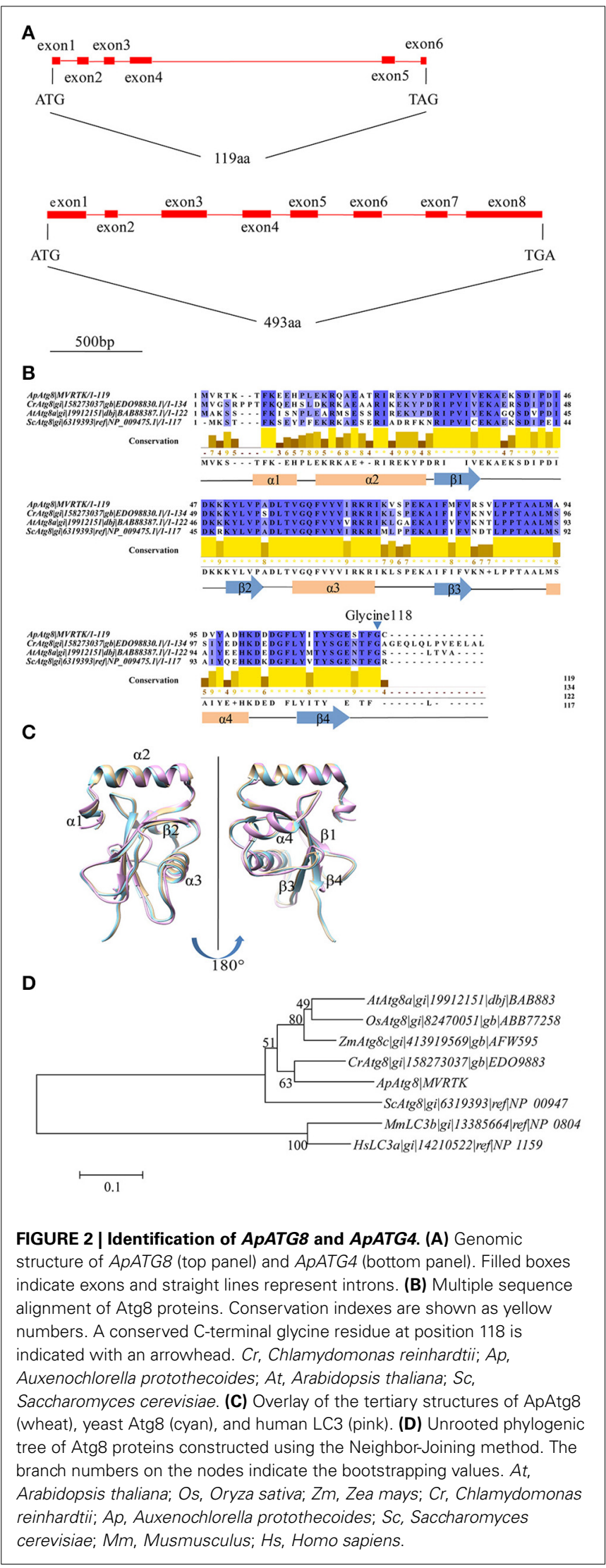




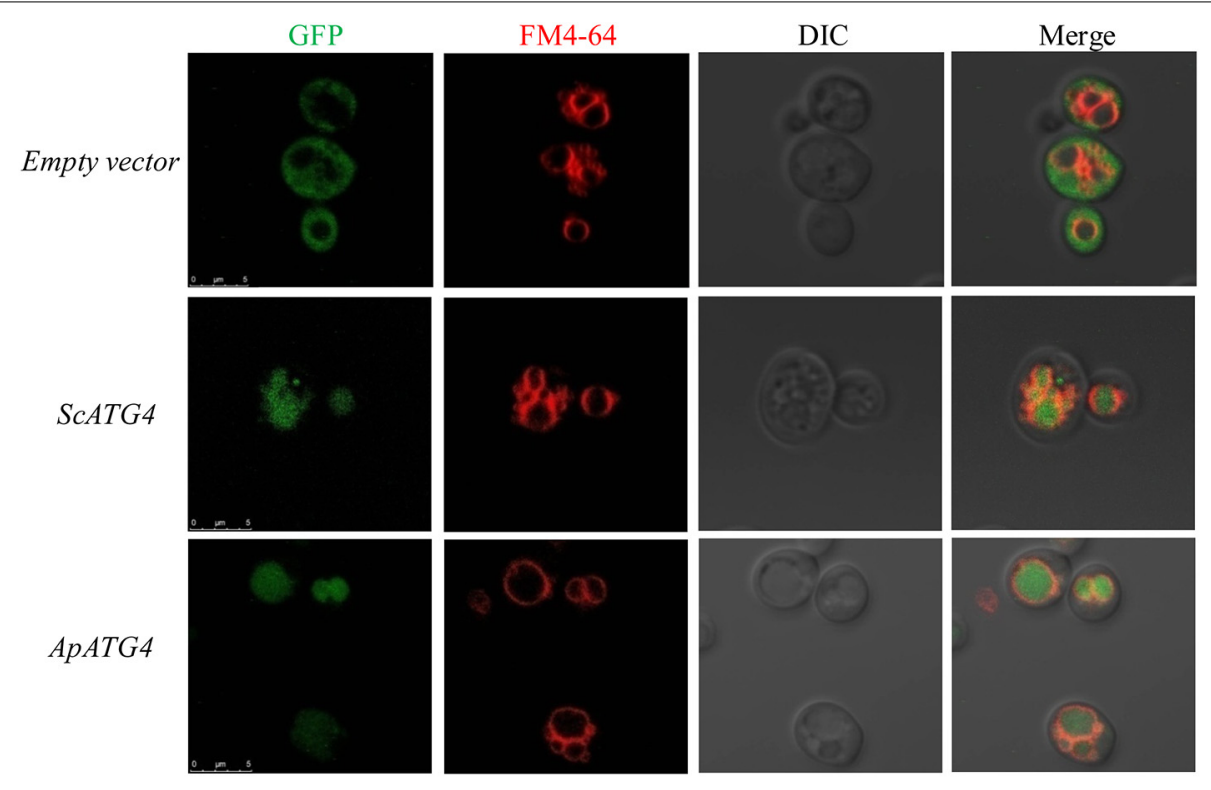

FIGURE 3 | Functional complementation of ApAtg4 in atg 4 mutant yeast. ApATG4 cDNA was cloned and expressed in a yeast atg 4 mutant in a GFP-Atg8 background. The yeast ATG4 (ScATG4) and the empty vector were used as positive and negative controls, respectively.
Log-phase cells were transformed into nitrogen starvation SD (-N) medium for $4 \mathrm{~h}$. The yeast vacuolar membrane was stained by FM4-64 DIC, Differential interference contrast microscopy images. Scale bar, $5 \mu \mathrm{m}$. and this was the likely target site for Atg4. To test this possibility, we constructed a reporter protein by fusing ApAtg8 with an N-terminal polyhistidine tag and a C-terminal GFP tag. In addition, plasmids were generated containing one of two mutant ApATG8 genes, one of which encoded a glycine to alanine substitution (G118A) and one of which encoded a glycine deletion $(\Delta \mathrm{G} 118)$ (Figure 4A). Fusion proteins and Atg4 from yeast (ScAtg4) and A. protothecoides (ApAtg4) were expressed in E. coli. An in vitro Atg8 cleavage assay was performed by mixing the whole-cell extracts from Atg8-expressing bacteria with whole-cell extracts from bacteria expressing ScAtg4, ApAtg4, or empty vector. Western blots were performed using anti-GFP antibody to detect free GFP (Figure 4B). Minimal free GFP was observed in the absence of Atg4. Free GFP was observed in increasing amounts with time when ApAtg8-GFP was incubated with Atg4 from yeast or A. protothecoides. The amount of ApAtg8-GFP fusion protein decreased concurrently. Liberation of free GFP did not occur when mutated ApAtg8-GFP (G118A or $\triangle \mathrm{G} 118$ ) was incubated with ApAtg4, indicating that cleavage of ApAtg8-GFP by Atg4 was dependent on ApAtg8 G118.

Next, we assessed whether Atg4 could cleave ApAtg8 in vivo. Fusion constructs were transformed and expressed in a yeast $\operatorname{atg} 8 \Delta$ strain and western analysis with anti-HIS antibody was used to identify free ApAtg8 protein. As shown in Figure 4C, ApAtg8-GFP was cleaved upon activation of autophagy by nitrogen starvation and a fragment of $\sim 18 \mathrm{kDa}$ was generated. This fragment size corresponded with the size of ApAtg8 protein. Mutant proteins containing either G118A or $\Delta$ G118 could not be processed. This indicated that, as with the in vitro analysis, G118 was essential for cleavage of ApAtg8. Cleavage was also completely abrogated in $\operatorname{atg} 4 \Delta$ yeast, which indicated that Atg 4 was also essential for processing of ApAtg8. Taken together, our data indicate that ApAtg8 can be cleaved by Atg4 in vitro and in vivo, and that Atg4 and ApAtg8 G118 are both necessary for processing.

\section{ApAtg8 CAN BE CONJUGATED TO PHOSPHATIDYLETHANOLAMINE IN VITRO}

After processing, Atg8 is conjugated to phosphatidylethanolamine $(\mathrm{PE})$ in a process crucial for autophagosome formation known as Atg8 lipidation. The Atg8 conjugation system was reconstituted in vitro using purified ATG proteins and liposomes to provide an experimental environment to assess ApAtg8 lipidation. Purified ApAtg8 ${ }^{\mathrm{G} 118}$, with C-terminal glycine exposed, was added to a reaction system containing purified yeast Atg7, Atg3, Atg5-Atg12, and 20\% PE liposomes. Yeast Atg8 ${ }^{\mathrm{G} 116}$ was used as a positive control and ApAtg8 ${ }^{\mathrm{C} 119}$ (no exposed C-terminal glycine) was used as a negative control. Urea-SDS-PAGE showed that the nascent form of ApAtg8 was detected as a single $\sim 16 \mathrm{kDa}$ fragment, as expected (Figure 5). A faster-migrating fragment, representing lipidated Atg8, was observed after incubation with ApAtg8 ${ }^{\mathrm{G} 118}$ or yeast Atg8 ${ }^{\mathrm{G} 116}$ for $15 \mathrm{~min}$. No lipidation was detected when the terminal glycine was masked (ApAtg8 ${ }^{\mathrm{C} 119}$ ). We therefore concluded that ApAtg8 could be conjugated to $\mathrm{PE}$ and that the conserved glycine at position mediated conjugation.

\section{ApAtg8 CAN BE RECRUITED TO THE PHAGOPHORE ASSEMBLY SITE IN YEAST}

After lipidation, Atg8 is recruited to the phagophore assembly site (PAS), where the core autophagy machinery was assembled. In yeast, Ape1 is recruited to PAS and is then transported to the vacuole for maturation by the cytoplasm to vacuole targeting 


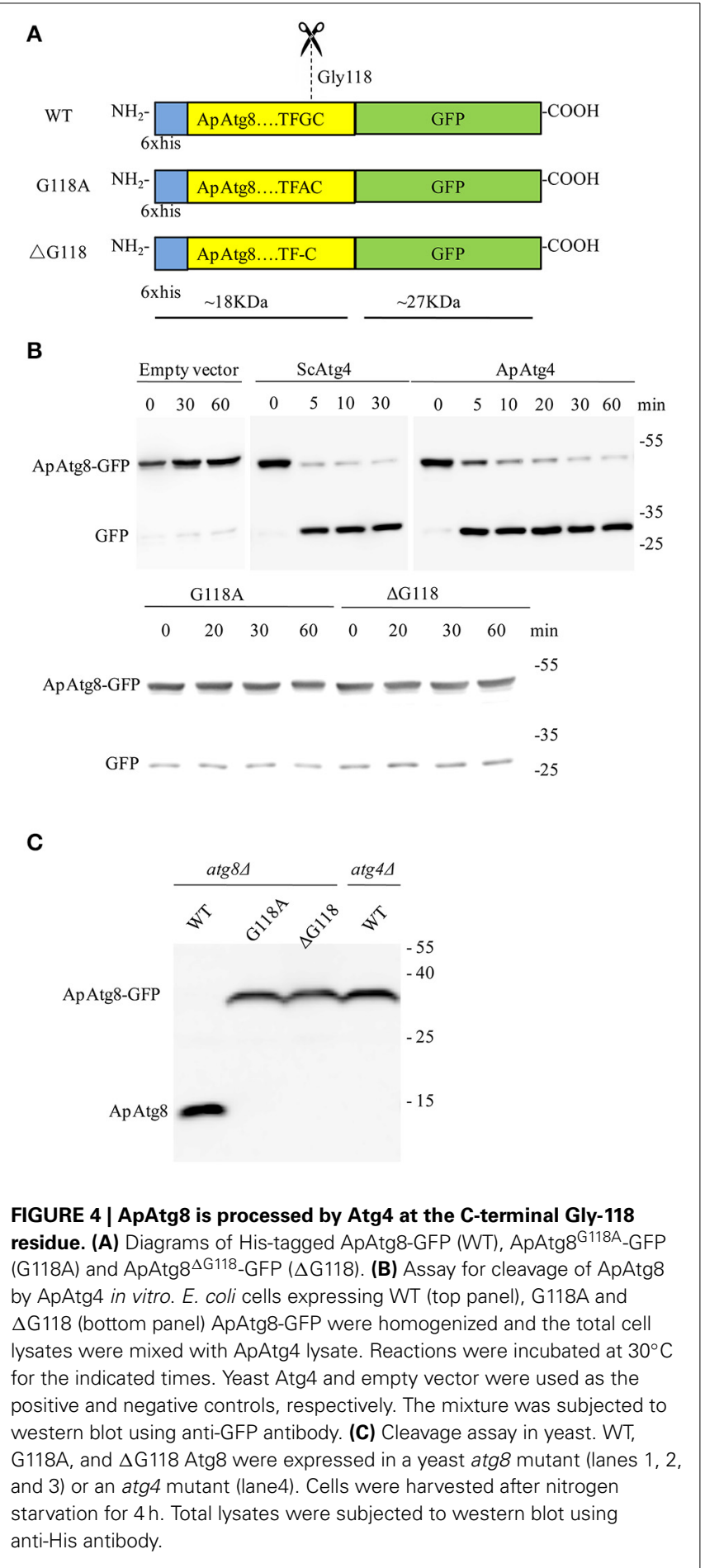

pathway (CVT). We wished to determine whether ApAtg8 could be recruited to PAS. Ape 1 co-localizes with Atg8 in yeast (van der Vaart et al., 2010) and we therefore examined co-localization of Ape1 and ApAtg8. GFP-labeled ApAtg8 and mCherry-labeled Ape1 were expressed in yeast cells and examined by fluorescence microscopy. GFP-alone was observed as diffuse green fluorescence and Ape1-mCherry was seen as spherical dots. As with yeast Atg8-GFP, ApAtg8-GFP formed punctate structures and co-localized with Ape1 after rapamycin treatment (Figure 6), indicating that ApAtg8 localized to the PAS during induction of autophagy in yeast.

\section{DEGRADATION OF LIPID BODIES AND BIOGENESIS OF THE PHOTOSYNTHETIC SYSTEM DURING THE HA TRANSITION}

We examined the morphological and biochemical component changes that occurred during the A. protothecoides HA transition. Algal cells were cultivated in heterotrophic media for 7 days, harvested, and used to inoculate autotrophic media (high nitrogen, glucose deprivation). Cells were stained for lipid using Nile red and were examined by confocal microscopy (Figure 7A). Large lipid bodies occupying more than half of the entire cellular space were typically found in heterotrophic cells at the initiation of the HA transition. The lipid bodies subsequently shrank in size and chlorophyll auto-fluorescence emerged during the first $24 \mathrm{~h}$ of adaptation to light. Assembly of chloroplastic structures was completed within $72 \mathrm{~h}$. Cup-shaped or spherical chloroplasts were dominant, which suggested that the photosynthetic system was completely reconstructed. Analysis of total cellular lipid and chlorophyll contents confirmed the degradation of lipid and biosynthesis of chlorophyll. The lipid content gradually decreased from $\sim 80 \%$ (w/w) at the initiation of the HA transition to $10 \%$ $(\mathrm{w} / \mathrm{w})$ after $72 \mathrm{~h}$ cultivation in autotrophic media. During the same time period, chlorophyll content increased to greater than $30 \mathrm{mg} / \mathrm{g}$ dry cell weight (Figure 7B).

\section{AUTOPHAGY INDUCTION DURING THE HA TRANSITION IN A. PROTOTHECOIDES}

To investigate whether autophagy is involved in the HA transition, cells at different time points were monitored using monodansylcadaverine (MDC), a fluorescent dye that stains the autophagic structures in vivo (Biederbick et al., 1995; Munafo and Colombo, 2001; Contento et al., 2005). Single-dye labeling samples were tested to ensure that bleed-through signal between filters did not occur (data not shown). The intensity of the MDC fluorescent signal increased $>5$-fold between 0 and 36/48 h (Figure 8A). Several MDC-labeled spherical structures were found in close proximity to the chloroplast envelope (Figures 8B,C). These mobile structures were probably autophagic bodies located randomly in the $A$. protothecoides vacuole. Cells containing MDC-labeled structures were quantitated, and numbers of MDC-positive cells rose during the $48 \mathrm{~h}$ after the shift to autotrophic growth. Approximately 15-fold more MDC-positive cells were found at $48 \mathrm{~h}$ than at $0 \mathrm{~h}$ (Figure $8 \mathrm{D} ;{ }^{*} p<0.03,{ }^{* *} p<0.01$ ).

To further confirm the presence of autophagic-like vacuoles in $A$. protothecoides during the HA transition, transmission electron microscopy was used to investigate ultrastructural changes within algal cells during transition. As shown in Figure 9A, the lipid bodies and starch granules that had accumulated in heterotrophic cells were degraded and the cup-shaped chloroplast was regenerated during the HA transition. This was consistent with the confocal microscopy observations. Autotrophic cells utilized plastoglobuli for lipid storage in chloroplasts (Figure 9A, white arrows). Electron-dense spherical structures and singlemembrane-bound vesicles $(\sim 0.3-1 \mu \mathrm{m}$ in diameter) that resembled autophagic bodies were typically detected in the vacuoles 


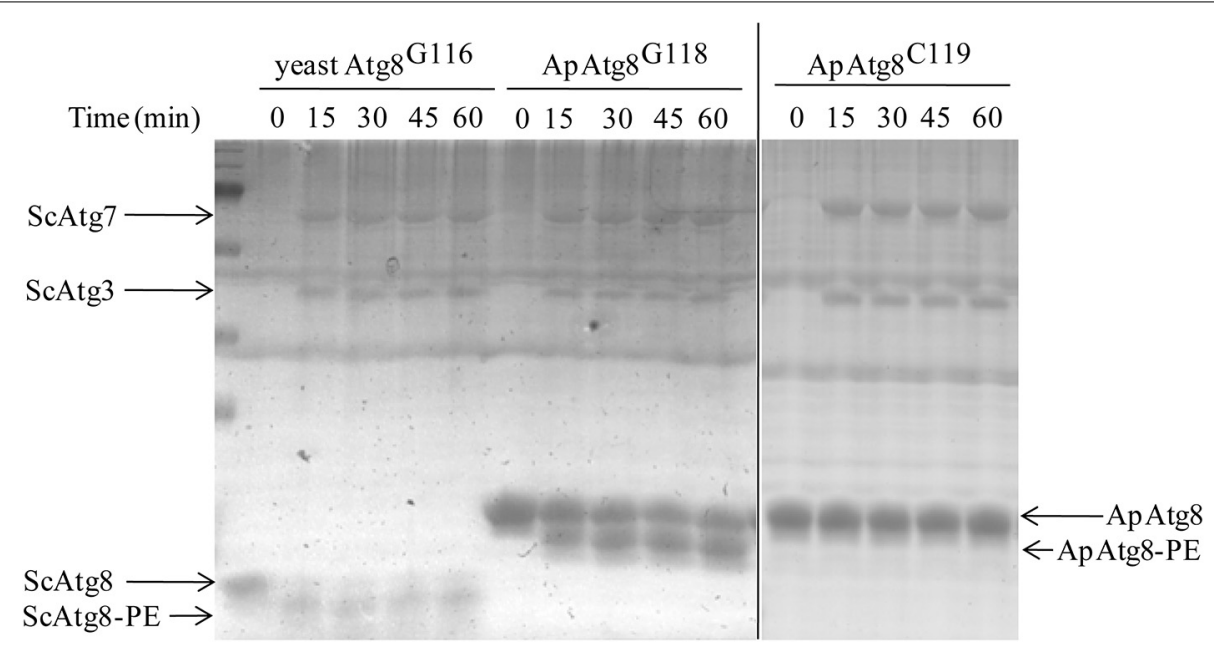

FIGURE 5 | In vitro lipidation of ApAtg8. In vitro conjugation reactions were performed at $30^{\circ} \mathrm{C}$ in the presence of purified yeast Atg3 (ScAtg3), Atg5, Atg7 (ScAtg7), ApAtg8 ${ }^{118}$ (the processed form of ApAtg8 whose
C-terminal glycine residue was exposed), and Atg12. Yeast $\mathrm{Atg} 8^{\mathrm{G} 116}$ and the nascent from of ApAtg8 (ApAtg8 ${ }^{C 119}$ ) were used as positive and negative controls, respectively.

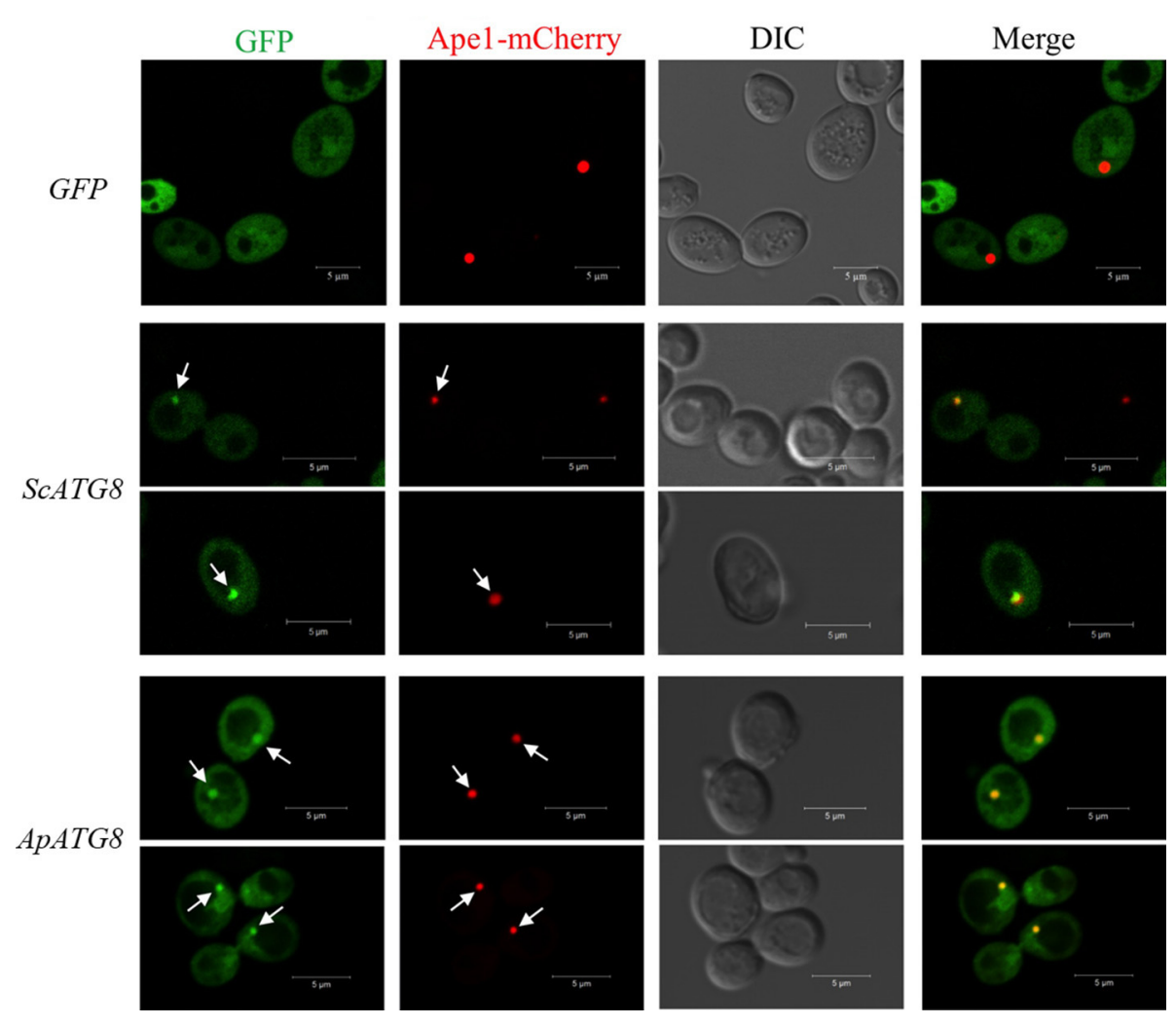

FIGURE 6| ApAtg8 co-localizes with Ape1 at the PAS. ApATG8 cDNA was expressed in atg8 $\triangle$ yeast. Yeast ATG8 (SCATG8) and the empty vector were used as positive and negative controls, respectively. Cells in log-phase were shifted to SC-uracil-leucine medium containing $0.2 \mu \mathrm{g} / \mathrm{ml}$ rapamycin for $1 \mathrm{~h}$. Arrows indicate the punctate structures where GFP-Atg8 and Ape1-mCherry co-localize. DIC, Differential interference contrast microscopy images. Scale bar, $5 \mu \mathrm{m}$. of HA cells subjected to autotrophic growth for 36 and $48 \mathrm{~h}$ but were absent within cells exposed to $0 \mathrm{~h}$ of light (Figures 9A,B). Smaller autophagic vacuoles generated within one single cell early in the HA transition subsequently fused into one large autophagic vacuole (Figure 9A). These data suggest that autophagy was induced during the HA transition. Instead of the large lipid bodies observed in the heterotrophic cells at $0 \mathrm{~h}$, a number of small lipid droplets (LDs) were seen in the proximity of the central 


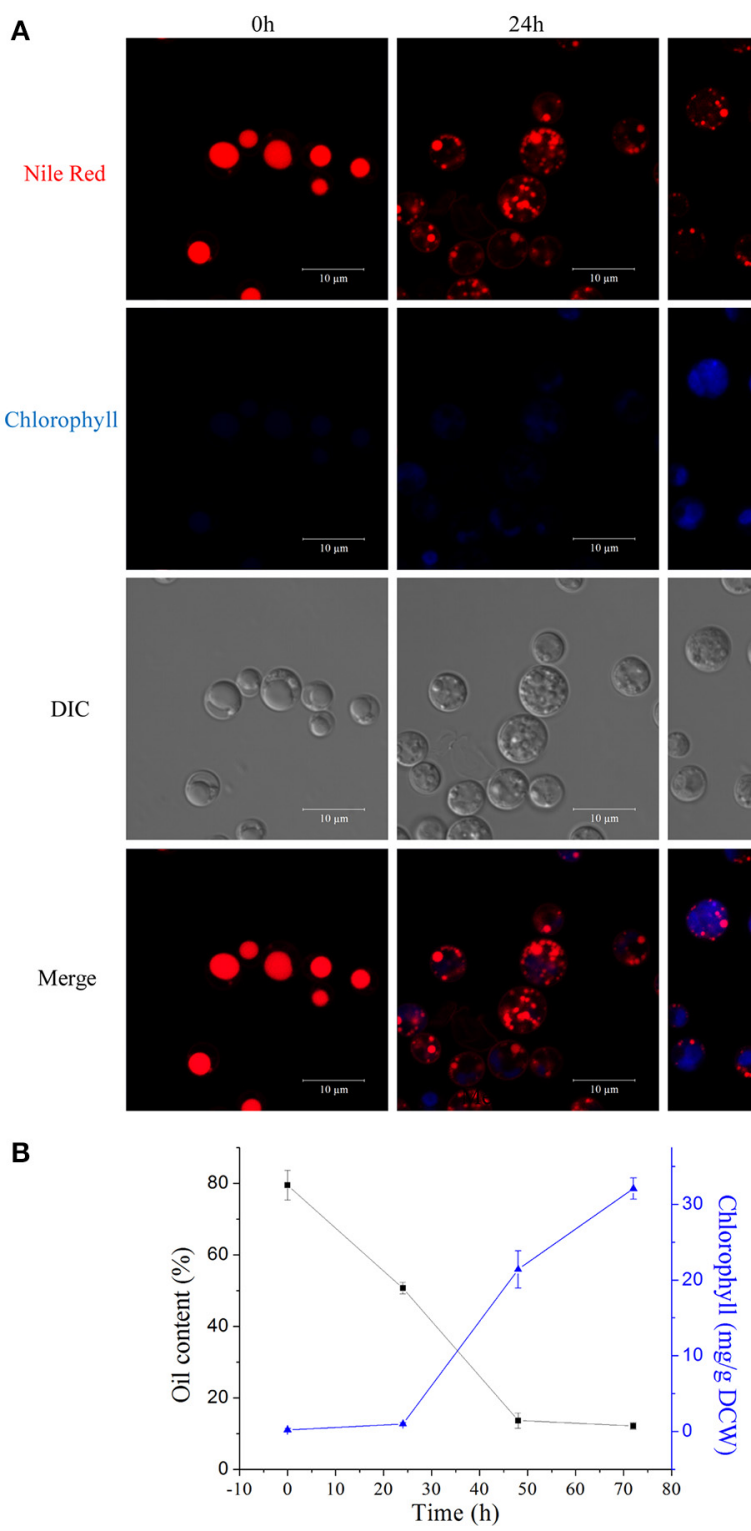

$36 h$
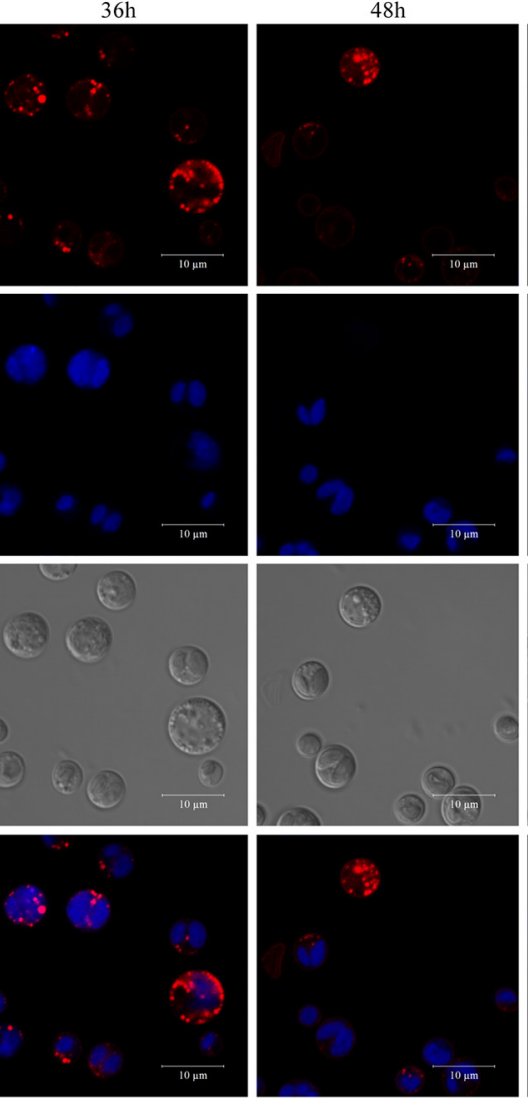

$72 \mathrm{~h}$
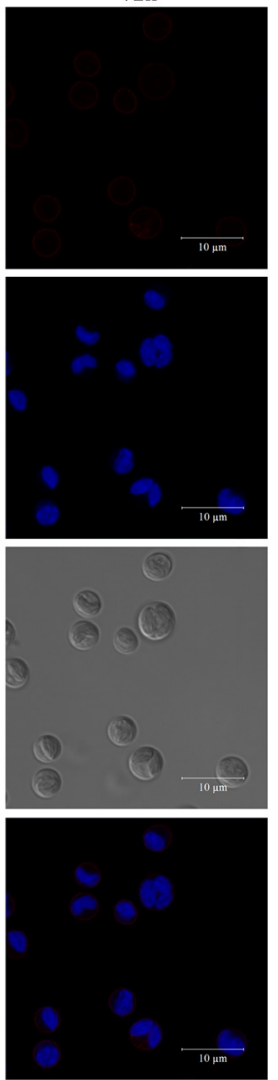

FIGURE 7 | Degradation of lipids and biogenesis of chloroplasts during the HA transition. (A) Confocal microscopy images of algal cells during the HA transition. Cells were cultivated in heterotrophic medium for 7 days and then transferred into autotrophic medium for 3 days. LDs were stained using
Nile red and chlorophyll auto-fluorescence is shown as a pseudo-color image in blue. DIC, Differential interference contrast microscopy images. Scale bar, $10 \mu \mathrm{m}$. (B) Determination of total lipid and chlorophyll contents of HA cells. Closed black square, lipid content; closed blue triangles, chlorophyll content. vacuole during the HA transition. These LDs, which were delimited by a single membrane, tended to be internalized by the larger (1.5 $\mu \mathrm{m}$ diameter) autophagic vacuole (Figures 9C-E). The different stages of LD internalization by autophagic vacuoles are shown in Figures 9F-I. A minority of LDs that were relatively large partially extruded into the autophagic vacuole (Figure 9G). Figures 9 H,I show LDs completely engulfed by autophagic vacuoles. To further confirm the autophagic degradation of lipid bodies in $A$. protothecoides during HA transition, cells were double-labeled with Nile red and MDC and examined with confocal microscopy. Lipid bodies in a number of cells exposed to light for 24-36 h co-localized with MDC-labeled structures, demonstrating that the dense bodies within vacuoles were likely to be LDs (Supplementary Figure 1). No double membrane structures consistent with lipophagy were detected, indicating that the degradation of LDs during HA transition in A. protothecoides was probably a microautophagy-like process.

\section{DISCUSSION}

Autotrophic and heterotrophic A. protothecoides undergo different growth patterns that result in diverse subcellular structures and chemical composition (Miao and Wu, 2006; Xiong et al., 2010; Lu et al., 2013). The majority of the cellular space in heterotrophic cells comprises large lipid droplets $(\sim 1-2 \mu \mathrm{m})$ and 


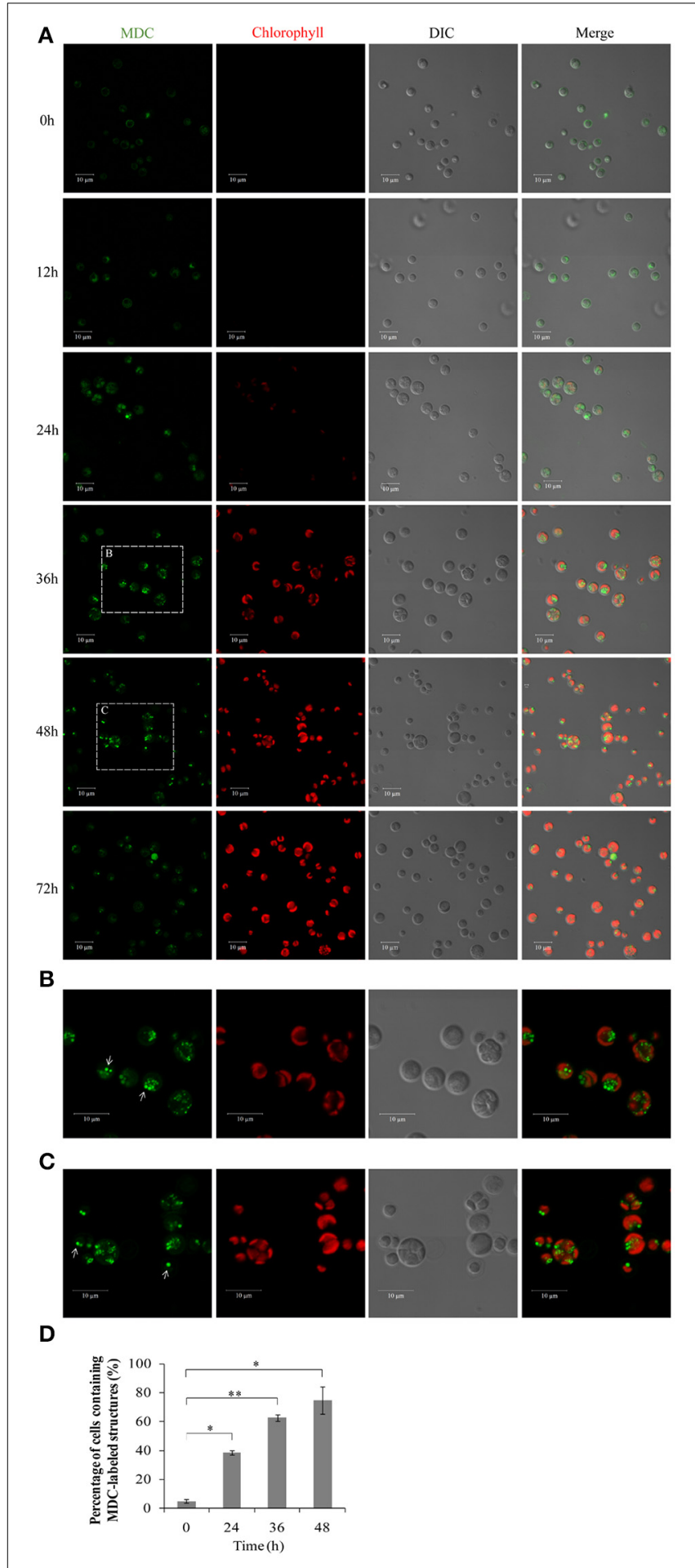

FIGURE 8 | Confocal microscope images of $\boldsymbol{A}$. protothecoides during the HA transition. (A) MDC staining of $A$. protothecoides. Seven-day heterotrophic cells were inoculated into autotrophic medium and exposed to light at $28^{\circ} \mathrm{C}$. Filtered air was supplied. Cells were harvested at the indicated times, stained with MDC, and observed using a confocal microscope. The MDC structures are shown in green and chlorophyll $A$ is shown in red. Scale bar, $10 \mu \mathrm{m}$. (B,C) Magnified images of

A. protothecoides cells from (A). Scale bar, $10 \mu \mathrm{m}$. White arrows indicate MDC-stained autophagic bodies. (D) Quantification of MDC-stained

(Continued)

\section{FIGURE 8 | Continued}

structures. More than 100 cells were counted each time and the percentage of cells containing MDC-labeled structures was calculated. Error bars represent standard error from two independent experiments. Student's $t$-test was used to determine significant differences $(* P<0.03$, ** $P<0.01)$.

starch granules and photosynthetic chloroplasts are completely absent. The neutral lipid content varies greatly between heterotrophic (above 50\%) and autotrophic ( $10 \%)$ cells. Algal cells have the ability to undergo HA transition, in which lipid droplets and starch granules diminish and the large cup-shaped chloroplast is regenerated. However, the mechanisms underlying the HA transition remain obscure. In this study, we demonstrated that autophagy-related genes in the ATG8-conjugating pathway were conserved in A. protothecoides. We also showed that an autophagy-like process was involved in the degradation of LDs during the HA transition. A. protothecoides may therefore serve as a useful study model for the metabolism and dynamics of lipid droplets and chloroplasts.

\section{CONSERVATION OF AUTOPHAGY-RELATED GENES IN A. PROTOTHECOIDES}

Previous studies revealed that autophagy-related pathways evolved in eukaryotes for the chambered-protease degradation of proteins and organelles (Hughes and Rusten, 2007). A. protothecoides is a eukaryotic green alga derived from primary endosymbiosis (Keeling et al., 2005). In this study, we performed a genome-wide in silico study of the autophagy machinery in A. protothecoides and provided evidence for the existence of most autophagy-related genes. This is consistent with our previous survey of autophagy-related genes in seven different microalgae (Jiang et al., 2012). These data suggest that autophagy is an evolutionarily ancient process.

We failed to identify several core autophagy components (Figure 1). As canonical autophagy genes were mainly identified in model organisms, such as yeast, one possible explanation is that the related autophagy pathways might not exist in A. protothecoides. Alternatively, these components may lack sufficient sequence conservation with their yeast counterparts to allow identification. Finally, some species-specific autophagy factors or pathways may exist that would compensate for the missing canonical components. In support of the last hypothesis, recent genetic screens of autophagy-deficient mutants in Caenorhabditis elegans reveal several uncharacterized metazoan-specific genes required for macroautophagy, including epg-2,-3,-4, and -5 (Tian et al., 2010). Further investigation will be required to test this possibility.

\section{HOW DO LIPID BODIES IN HETEROTROPHIC ALGAL CELLS DEGRADE?}

Previous studies reveal that LDs perform functions other than lipid storage. LDs are dynamic multifunctional organelles that are involved in various physiological pathways, including membrane synthesis, viral replication, protein degradation, and energy production (Walther and Farese, 2012). Disorders in the metabolism of LDs, particularly those involving excessive LD storage in mammalian tissues, are related to several diseases such as diabetes and 

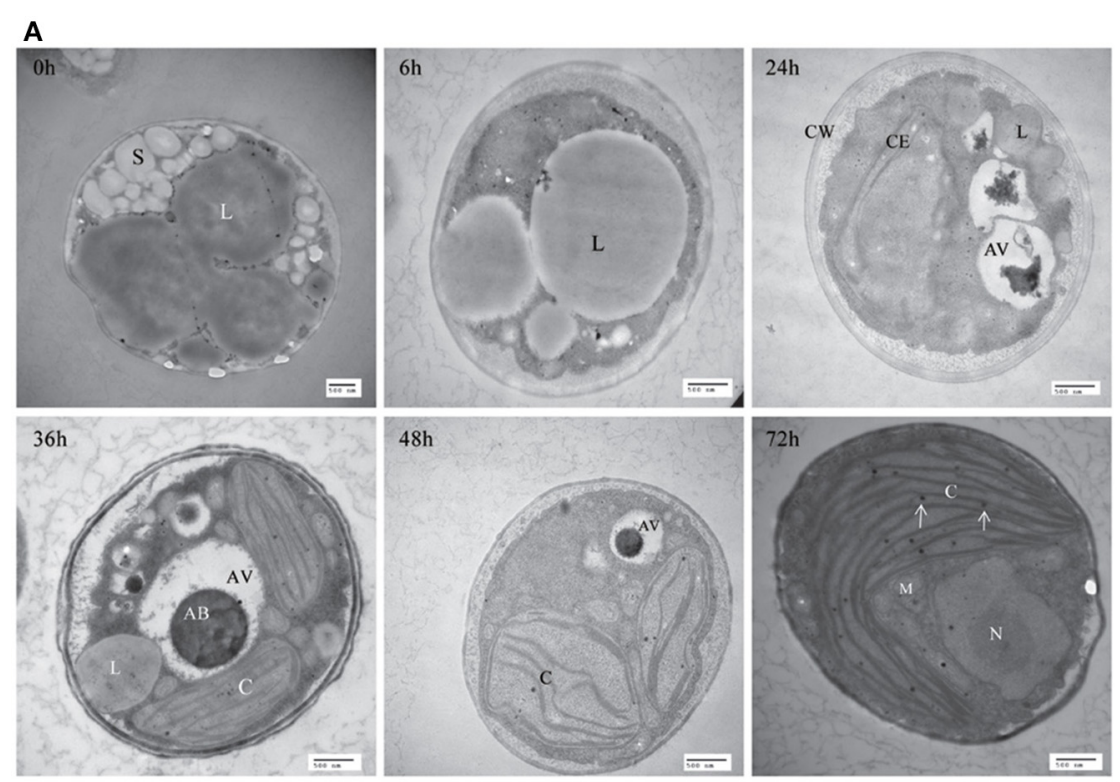

B

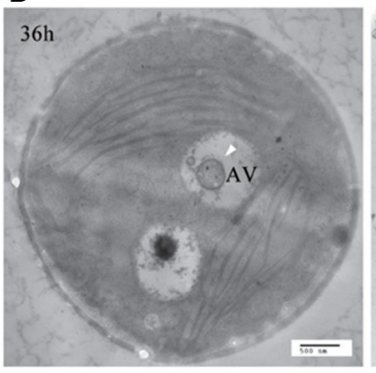

E

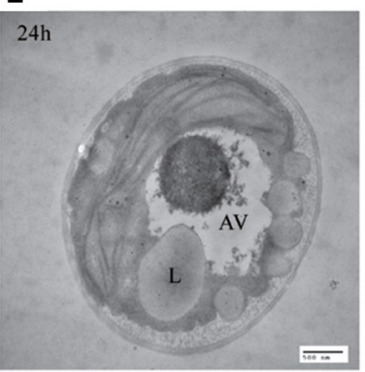

H

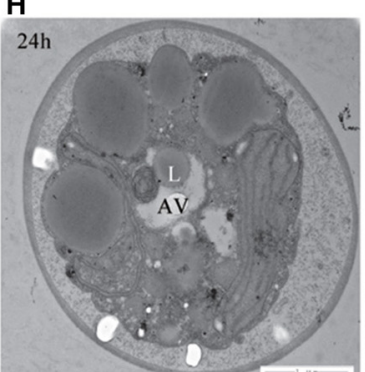

\section{C}

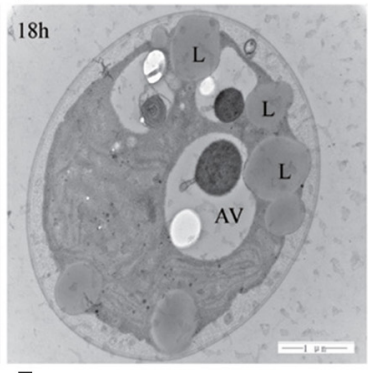

\section{$\mathbf{F}$}

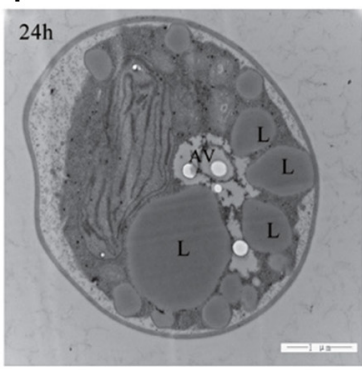

I

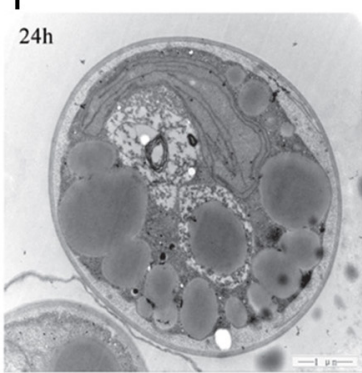

D

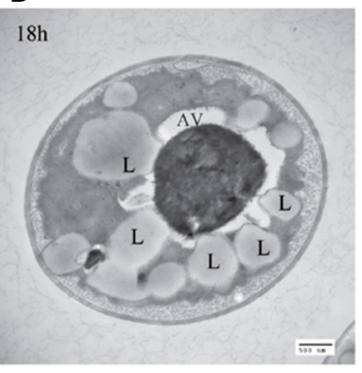

G
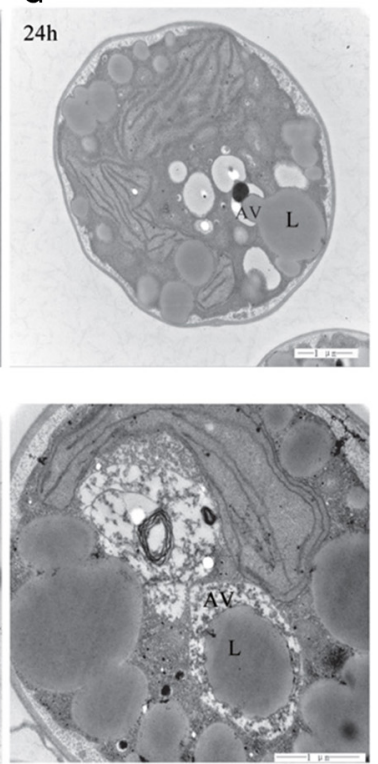

FIGURE 9 | Transmission electron microscope (TEM) images of

$\boldsymbol{A}$. protothecoides during the HA transition. (A) Heterotrophic cells were resuspended in autotrophic medium for the indicated time and then processed for TEM. C, chloroplast; CE, chloroplast envelope; CW, cell wall; $\mathrm{S}$, starch granules; $L$, lipid bodies; $A V$, autophagic vacuoles; $A B$, autophagic bodies; M, mitochondria; $N$, nuclear. White arrows indicate plastoglobuli in chloroplasts. (B) Representative ultrastructure of autophagic vacuoles in HA cells after $36 \mathrm{~h}$ cultivation in autotrophic media. Single-membrane-bound vesicles (white arrowhead) were detected within the vacuoles of HA cells.

(C-I) Different stages of internalization of the small scattered LDs by autophagic vacuoles in A. protothecoides exposed to light for 18 or $24 \mathrm{~h}$ during the HA transition. L, lipid bodies; AV, autophagic vacuoles. 
atherosclerosis. LDs are hydrolyzed in a process called lipolysis by a series of cytosolic lipases such as adipose triglyceride lipase (ATGL), hormone sensitive lipase (HSL) in mammals, and Tg13\& Tg14 in yeast (Fujimoto and Parton, 2011). More recently, autophagy is shown to contribute to the breakdown of LDs for the maintenance of lipid homeostasis in mouse liver, plant seeds, and fungi (Singh et al., 2009; Kurusu et al., 2014; van Zutphen et al., 2014).

In this study, we found that LDs were directly sequestered by the $A$. protothecoides vacuole during the HA transition. This occurred via a microautophagy-resembling pathway that involved the protrusion of the vacuolar membrane rather than engulfment by double membrane structures such as autophagosomes. However, the vacuole was not large enough to entirely engulf the lipid bodies during early stages of HA transition. TEM images suggested that the cells might adopt two strategies to break down large LDs. The first step involves lipolysis, in which the large lipid bodies are disintegrated by LD-resident TAG lipases into many small-sized LDs. Alternatively, a portion of the large lipid bodies might protrude into the autophagic vacuole, be pinched off into the vacuolar lumen, and then be hydrolyzed by vacuolar lipase. The partial sequestration of organelles by the autophagic vacuole in yeast has been described previously for piecemeal microautophagy of the nucleus (PMN) (Roberts et al., 2003). In the second step, small LDs could be integrally incorporated into the central vacuole for autophagy degradation by inward invagination. This resembles lipid autophagy in yeast and is distinct from lipid metabolism in mammalian cells and plant seeds. The lipolysis and microautophagy pathways are therefore delicately orchestrated in $A$. protothecoides during the HA transition to satisfy the demands of lipid metabolism and energy supply.

\section{WHAT INDUCES AUTOPHAGY DURING THE HA TRANSITION?}

Due to the inclusion of glucose, the heterotrophic cultivation medium used for $A$. protothecoidesis relatively nutritious compared to the medium used for autotrophic growth. As a result, cells probably undergo carbon starvation upon transfer into glucose-free autotrophic media during the delay before a functioning chloroplast is established. Carbon starvation may serve as an inducer to trigger autophagy in a similar manner to the classic nitrogen starvation signal found in other organisms. Autophagy could be induced in A. protothecoides during the HA transition to allow cells to generate enough energy to propagate and to rebuild the photosynthetic machinery. Similar phenomena have been reported in other systems such as tobacco BY-2 cells and Arabidopsis suspension cells during sucrose starvation (Takatsuka et al., 2004; Rose et al., 2006). However, no evidence linking autophagy to lipid degradation was presented in those studies.

\section{ACKNOWLEDGMENTS}

We are grateful to Cong Yi for providing the yeast strains, Shaojin Zhang for providing purified yeast ATG proteins and lipososmes, Jingjing Tong for suggestions and assistance in experiments and Diane C. Bassham for helpful discussion and critical comments. This work was supported by NSFC project 31370282 and 41030210, MOST project 2011BAD14B05 and 2014AA02200 to Qingyu Wu and by Tsinghua University Initiative Scientific Research Program $2012 Z 08128$ to Junbiao Dai.

\section{SUPPLEMENTARY MATERIAL}

The Supplementary Material for this article can be found online at: http://www.frontiersin.org/journal/10.3389/fpls.2014.00400/ abstract

\section{REFERENCES}

Affenzeller, M. J., Darehshouri, A., Andosch, A., Lutz, C., and Lutz-Meindl, U. (2009). Salt stress-induced cell death in the unicellular green alga Micrasterias denticulate. J. Exp. Bot. 60, 939-954. doi: 10.1093/jxb/ ern348

Andosch, A., Affenzeller, M. J., Lütz, C., and Lütz-Meindl, U. (2012). A freshwater green alga under cadmium stress: ameliorating calcium effects on ultrastructure and photosynthesis in the unicellular model Micrasterias. J. Plant Physiol. 169, 1489-1500. doi: 10.1016/j.jplph.2012.06.002

Biederbick, A., Kern, H. F., and Elsasser, H. P. (1995). Monodansylcadaverine (MDC) is a specific in vivo marker for autophagic vacuoles. Eur. J. Cell Biol. $66,3-14$.

Contento, A. L., Xiong, Y., and Bassham, D. C. (2005). Visualization of autophagy in Arabidopsis using the fluorescent dye monodansylcadaverine and a GFP-AtATG8e fusion protein. Plant J. 42, 598-608. doi: 10.1111/j.1365313X.2005.02396.x

Eyden, B. P. (1975). Light and electron microscope study of Dunaliella primolecta butcher (Volvocida). J. Protozool. 22, 336-344. doi: 10.1111/j.15507408.1975.tb05183.x

Fujimoto, T., and Parton, R. G. (2011). Not just fat: the structure and function of the lipid droplet. Cold Spring Harb. Perspect. Biol. 3:a004838. doi: 10.1101/ cshperspect.a004838

Gao, C., Wang, Y., Shen, Y., Yan, D., He, X., Dai, J., et al. (2014). Oil accumulation mechanisms of the oleaginous microalga Chlorella protothecoides revealed-through its genome, transcriptomes and proteomes. BMC Genomics 15:582-595. doi: 10.1186/1471-2164-15-582

Hanaoka, H., Noda, T., Shirano, Y., Kato, T., Hayashi, H., Shibata, D., et al. (2002) Leaf senescence and starvation-induced chlorosis areaccelerated by the disruption of an Arabidopsis autophagy gene. Plant Physiol. 129, 1181-1193. doi: 10.1104/pp.011024

Hughes, T., and Rusten, T. E. (2007). Origin and evolution of self-consumption: autophagy. Adv. Exp. Med. Biol. 607, 111-118. doi: 10.1007/978-0-38774021-8_9

Ichimura, Y., Imamura, Y., Emoto, K., Umeda, M., Noda, T., and Ohsumi, Y. (2004). In vivo and in vitro reconstitution of Atg8 conjugation essential for autophagy. J. Biol. Chem. 279, 40584-40592. doi: 10.1074/jbc.M405860200

Inwood, W., Yoshihara, C., Zalpuri, R., Kim, K. S., and Kustu, S. (2008).The ultrastructure of a Chlamydomonas reinhardtii mutant strain lacking phytoene synthase resembles that of a colorless alga. Mol. Plant 1, 925-937. doi: $10.1093 / \mathrm{mp} / \mathrm{ssn} 046$

Jiang, Q., Zhao, L., Dai, J. B., and Wu, Q. Y. (2012). Analysis of autophagy genes in microalgae: Chlorella asa potential model to study mechanism of autophagy. PLoS ONE 7:e41826. doi: 10.1371/journal.pone.0041826

Jimenez, C., Capasso, J. M., Edelstein, C. L., Rivard, C. J., Lucia, S., Breusegem, S., et al. (2009). Different ways to die: cell death modes of the unicellular chlorophyte Dunaliella viridis exposed to various environmental stresses are mediated by the caspase-like activity DEVDase. J. Exp. Bot. 60, 815-828. doi: 10.1093/jxb/ern330

Keeling, P. G., Burger, G., Durnford, D. G., Lang, B. F., Lee, R. W., Pearlman, R. E., et al. (2005). The tree of eukaryotes. Trends Ecol. Evol. 20, 670-676. doi: 10.1016/j.tree.2005.09.005

Kirisako, T., Ichimura, Y., Okada, H., Kabeya, Y., Mizushima, N., Yoshimori, T., et al. (2000). The reversible modification regulates the membrane-binding state ofApg8/Aut7 essential for autophagy and the cytoplasm to vacuole targeting pathway. J. Cell Biol. 151, 263-275. doi: 10.1083/jcb.151.2.263

Kurusu, T., Koyano, T., Hanamata, S., Kubo, T., Noguchi, Y., Yagi, C., et al. (2014). OsATG7 is required for autophagy-dependent lipid metabolism in rice postmeiotic anther development. Autophagy 10, 878-888. doi: 10.4161/auto. 28279 
Lazinsky, D., and Sicko-Goad, L. (1990). Morphometric analysis of phosphate and chromium interactions in Cyclotella meneghiniana. Aquat. Toxicol. 16, 127-140. doi: 10.1016/0166-445X(90)90082-Z

Lilienbaum, A. (2013). Relationship between the proteasomal system and autophagy. Int. J. Biochem. Mol. Biol. 4, 1-26.

Liu, Y., and Bassham, D. C. (2012). Autophagy: pathways forself-eating in plant cells. Annu. Rev. Plant Biol. 63, 215-237. doi: 10.1146/annurev-arplant-042811105441

Lu, Y., Dai, J. B., and Wu, Q. (2013). Photosynthesis-fermentation hybrid system to producelipid feedstock for algal biofuel. Environ. Technol. 34, 1869-1876. doi: 10.1080/09593330.2013.824011

Meijer, W. H., van der Klei, I. J., Veenhuis, M., and Kiel, J. A. K. W. (2007). ATG genes involved in non-selective autophagy are conserved from yeast to man, but the selective Cvt and pexophagy pathways also require organism-specific genes. Autophagy 3, 106-116. doi: 10.4161/auto.3595

Miao, X. L., and Wu, Q. Y. (2006). Biodiesel production from heterotrophic microalgal oil. Bioresour. Technol. 97, 841-876. doi: 10.1016/j.biortech.2005.04.008

Mizushima, N. (2007). Autophagy: process and function. Gene Dev. 21, 2861-2873. doi: 10.1101/gad.1599207

Mizushima, N., and Komatsu, M. (2011). Autophagy: renovation of cells and tissues. Cell 147, 728-741. doi: 10.1016/j.cell.2011.10.026

Munafo, D. B., and Colombo, M. I. (2001). A novel assay to study autophagy: regulation of autophagosome vacuole size by amino acid deprivation. J. Cell Sci. 114, 3619-3629.

Perez-Perez, M. E., Couso, I., and Crespo, J. L. (2012). Carotenoid deficiency triggers autophagy in the model green alga Chlamydomonas reinhardtii. Autophagy 8, 376-388. doi: 10.4161/auto.18864

Perez-Perez, M. E., Florencio, F. J., and Crespo, J. L. (2010).Inhibition of target of rapamycin signaling and stress activate autophagy in Chlamydomonas reinhardtii. Plant Physiol. 152, 1874-1888. doi: 10.1104/pp.109. 152520

Roberts, P., Moshitch-Moshkovitz, S., Kvam, E., O’Toole, E., Winey, M., and Goldfarb, D. S. (2003). Piecemeal microautophagy of nucleus in Saccharomyces cerevisiae. Mol. Biol. Cell 14, 129-141. doi: 10.1091/mbc.E02-08-0483

Rose, T. L., Bonneau, L., Der, C., Marty-Mazars, D., and Marty, F. (2006). Starvation-induced expression of autophagy-related genes in Arabidopsis. Biol. Cell 98, 53-67. doi: 10.1042/BC20040516

Sicko-Goad, L., Evans, M. S., Lazinsky, D., Hall, J., and Simmons, M. S. (1989). Effects of chlorinated benzenes on diatom fatty acid composition and quantitative morphology. IV. Pentachlorobenzene and comparison with trichlorobenzeneisomers. Arch. Environ. Contam. Toxicol. 18, 656-668. doi: 10.1007/BF01225004

Singh, R., Kaushik, S., Wang, Y. J., Xiang, Y. Q., Novak, I., Komatsu, M., et al. (2009). Autophagy regulates lipid metabolism. Nature 458, 1131-1135. doi: 10.1038/nature07976

Takatsuka, C., Inoue,Y., Matsuoka,K., and Moriyasu,Y. (2004). 3-Methyladenine inhibits autophagy in tobacco culture cells under sucrose starvation conditions. Plant Cell Physiol. 45, 265-274. doi: 10.1093/pcp/pch031
Tian, T., Li, Z. P., Hu, W. Q., Ren, H. Y., Tian, E., Zhao, Y., et al. (2010). C. elegans screen identifies autophagy genes specific to multicellular organisms. Cell 141, 1042-1055. doi: 10.1016/j.cell.2010.04.034

Tsukada, M., and Ohsumi, Y. (1993). Isolation and characterization of autophagydefective mutants of Saccaromyces cerevisiae. FEBS Lett. 333, 169-174. doi: 10.1016/0014-5793(93)80398-E

van der Vaart, A., Griffith, J., and Reggiori, F. (2010). Exit from the golgi is required for the expansion of the autophagosomal phagophore in yeast Saccharomy cescerevisiae. Mol. Biol. Cell 21, 2270-2284. doi: 10.1091/mbc.E09-04-0345

van Zutphen, T., Todde, V., der Boer, R., Kreim, M., Hofbauer, H. F.,Wolinski, H., et al. (2014). Lipid droplet autophagy in the yeast Saccharomyces cerevisiae. Mol. Biol. Cell 25, 290-301. doi: 10.1091/mbc.E13-08-0448

Walther, T. C., and Farese, R. V. Jr. (2012). Lipid droplets and cellular lipid metabolism. Annu. Rev. Biochem. 81, 687-714. doi: 10.1146/annurev-biochem061009-102430

Weber, R. W., Wakley, G. E., Thines, E., and Talbot, N. J. (2001). The vacuole as central element of the lytic system and sink for lipid droplets in maturing appressoria of Magnaporthe grisea. Protoplasma 216, 101-112. doi: 10.1007/BF02680137

Xia, K. F., Liu, T., Ouyang, J., Wang, R., Fan, T., and Zhang, M. Y. (2011). Genomewide identification, classification, and expression analysis of autophagyassociated gene homologs in rice (Oryza sativa L.). DNA Res. 18, 363-377. doi: 10.1093/dnares/dsr024

Xia, Z. P., and Klionsky, D. J. (2007). Autophagosome formation: core machinery and adaptations. Nat. Cell Biol. 9, 1102-1109. doi: 10.1038/ncb1007-1102

Xiong, W., Gao, C. F., Yan, D., Wu, C., and Wu, Q. Y. (2010). Double $\mathrm{CO}_{2}$ fixation in photosynthesis-fermentation model enhances algal lipid synthesis for biodiesel production. Bioresour. Technol. 101, 2287-2293. doi: 10.1016/j.biortech.2009.11.041

Yang, Z. F., and Klionsky, D. J. (2009). An overview of the molecular mechanism of autophagy. Curr. Top. Microbiol. Immunol. 335, 1-32. doi: 10.1007/978-3-64200302-8_1

Conflict of Interest Statement: The authors declare that the research was conducted in the absence of any commercial or financial relationships that could be construed as a potential conflict of interest.

Received: 04 June 2014; accepted: 28 July 2014; published online: 14 August 2014. Citation: Zhao L, Dai J and Wu Q (2014) Autophagy-like processes are involved in lipid droplet degradation in Auxenochlorella protothecoides during the heterotrophyautotrophy transition. Front. Plant Sci. 5:400. doi: 10.3389/fpls.2014.00400

This article was submitted to Plant Cell Biology, a section of the journal Frontiers in Plant Science.

Copyright (c) 2014 Zhao, Dai and Wu. This is an open-access article distributed under the terms of the Creative Commons Attribution License (CC BY). The use, distribution or reproduction in other forums is permitted, provided the original author(s) or licensor are credited and that the original publication in this journal is cited, in accordance with accepted academic practice. No use, distribution or reproduction is permitted which does not comply with these terms. 